\title{
Fetal Intravenous Nutritional Supplementation Ameliorates the Development of Embolization- Induced Growth Retardation in Sheep ${ }^{1}$
}

\author{
VALERIE CHARLTON AND MICHAEL JOHENGEN
}

Department of Pediatrics, University of California Medical Center, San Francisco, California 94143

\begin{abstract}
Since decreased transfer of nutrients into the fetus has been documented in many forms of intrauterine growth retardation, we evaluated whether increasing fetal nutrient availability would prevent the development of experimental growth retardation in fetal lambs. Fetuses were separated into three groups: $E$, animals growth retarded by repetitive uteroplacental embolization $(n=8)$; ES, animals treated as in $E$ and given fetal femoral venous infusions of $5 \%$ glucose and $6.8 \%$ amino acids $(n=7)$; and $C$, controls $(n=8)$. The duration and density of embolization were the same in $E$ and $E S$; initial physical and metabolic characteristics and gestation at delivery were similar in all groups. $\mathrm{E}$ birth weight was reduced $26 \%$ compared to $\mathrm{C}(2888 \pm 373 \mathrm{SEM} \mathrm{g}$ versus $3880 \pm 277 \mathrm{~g}$, $p<0.05$ ); fetal/maternal weight ratio was decreased $35 \%$ $(p<0.005)$ and ponderal index decreased $22 \%(p<0.005)$. Asymmetric growth retardation was indicated in $\mathrm{E}$ by an increased brain/body weight ratio $(p<0.05)$. ES fetuses, in contrast, showed no differences from $C$ in birth weight $(3601 \pm 190 \mathrm{~g})$ or body proportions. ES were larger than $\mathrm{E}$, with a greater fetal/maternal weight ratio and ponderal index $(p<0.05$ for both). In E and ES, size at birth showed a positive relation to the amount of supplements received. The average daily supplementation rate correlated with the fetal/maternal weight ratio and with the ponderal index (for both $r=0.62, p<0.02$ ). Within the ES group alone there was a marked correlation between the average daily supplementation rate and birth weight $(r=0.97, p<$ 0.001). Placental weight was reduced $36 \%$ in $E$ versus $C$, but was maintained in ES $(p<0.02 \mathrm{E}$ versus $\mathrm{ES}, p<0.05$ $E$ versus $C$ ). In $E$ and $E S$, placental size correlated with the volume of supplements received by the mid-third trimester $(r=0.84, p<0.001)$. Along with the reduction in placental size, umbilical blood flow was decreased $27 \%$ in $\mathrm{E}$ versus $\mathrm{ES}(p<0.05)$. Nutrient availability appeared to be a major determinant of the development of fetal and placental growth retardation in this study. However, the specific nutritional or metabolic factors leading to improved growth could not be identified. (Pediatr Res 22: 55-61, 1987)
\end{abstract}

\section{Abbreviations}

$E$, placental embolization

ES, placental embolization with fetal nutritional supplementation

$C$, nonembolized controls

Received August 25, 1986; accepted February 11,1987

Correspondence and reprints requests Valerie Charlton, M.D., University of California, Room 587U, Box 0748, San Francisco, CA 94143

Supported by National Institutes of Health Grant HD11109 and an NIH Research Career Development Award to V.C.

' Presented in part at the Society for Pediatric Research, May 1986.
Intrauterine growth retardation is a major cause of perinatal mortality (1). Many forms of growth retardation appear to be due to inadequate availability of nutrients in utero (2) and decreased maternal to fetal transfer of nutrients has been demonstrated in experimentally growth retarded fetal animals (2-7). We have previously found that chronic fetal intragastric supplementation, with glucose and amino acids, prevents the development of growth retardation in fetal lambs of diet restricted ewes (3). The current study was undertaken to determine whether fetal intravascular supplementation would also prevent the development of a more severe form of growth retardation, that induced by direct placental damage. We found that chronic infusion of glucose and amino acids normalized both fetal and placental size at birth.

\section{MATERIALS AND METHODS}

Surgical preparation. Prior to arrival at our sheep facility, early 3 rd trimester, breed-dated pregnant sheep were randomly assigned to one of three treatment groups: 1) E; 2) ES; and 3) C. All ewes were $x$-rayed and diagnosed as carrying a singleton gestation. On arrival the ewes were weighed and then fasted for $24 \mathrm{~h}$ before operative preparation.

Surgery was performed at a mean of $114 \pm 1$ (SEM) days gestation, as has been previously described (8). Spinal anesthesia was induced with $2.0 \mathrm{ml}$ of $1 \%$ tetracaine hydrochloride and analgesia was provided with intravenous pentobarbital $(65 \mathrm{mg} /$ $\mathrm{ml})$ as needed. A polyvinyl catheter $(0.050$ inch inner diameter and 0.090 inch outer diameter) was placed in the maternal femoral artery. The uterus was then exposed through a midline abdominal incision. After the uterus was opened, the fetal hindlimbs were exteriorized and measured distally (from hock to hoof). Local anesthesia, induced with $1 \%$ xylocaine, was used for all fetal incisions. Catheters $(0.030$ inch inner diameter and 0.048 inch outer diameter) were inserted into the femoral artery and vein of one hindlimb. An additional catheter was placed in a major umbilical vein, close to the fetal abdomen, by threading it up through a peripheral umbilical vein. Fetuses assigned to receive nutritional supplementation (group ES) had a second femoral venous catheter placed in the second hindlimb. An openended, basket style catheter (9) was inserted in the amniotic cavity and the uterus was closed. Animals designated to receive placental embolization (groups E and ES) had a catheter $(0.030$ inch inner diameter and 0.048 inch outer diameter) positioned in the main uterine artery supplying the pregnant uterine horn, by threading it retrograde from a peripheral uterine artery. Correct positioning of this catheter was verified at surgery by direct palpation and reverified at the completion of the study by arterial dissection. All catheters were brought out through a stab wound in the maternal flank and were protected by a mesh pocket. Penicillin ( 1 million units) and kanamycin $(200 \mathrm{mg})$ were given to the ewe intravenously and were also instilled into the amniotic 
cavity. Antibiotic administration was repeated for 3 to 5 days after surgery. Catheters were flushed with heparin $(1000 \mathrm{U} / \mathrm{ml})$ daily.

Study protocol. After surgery the ewes were fed ad libitum on alfalfa meal and water. They were accustomed to our laboratory environment by daily handling and catheter flushing. Maternal weights were measured weekly. All studies were carried out in the midday with the mothers in familiar moveable pens. Initial metabolic studies were performed after the ewes had recovered from surgery for a mean of 6 days (range 3-9). At study, blood samples were drawn from the maternal artery and simultaneously from the fetal femoral artery and umbilical vein. Analyses were carried out for whole blood concentrations of glucose, amino acids (measured as $\alpha$-amino-nitrogen), lactate, urea nitrogen, hemoglobin, oxygen saturation, $\mathrm{pH}$, and $\mathrm{PaO}_{2}$. Two complete sets of metabolite and blood gas measurements were made and averaged to obtain a study value. Fetuses that were acidotic or hypoxic, with a femoral arterial pH $<7.30$ or $\mathrm{PaO}_{2}<18 \mathrm{~mm}$ $\mathrm{Hg}$, at the time of these baseline measurements were eliminated from the experimental protocol.

After the initial studies were completed, placental embolization was begun in groups $\mathrm{E}$ and ES. One to two million, $15 \mu$ in diameter, carbonized spheres were injected into the uterine artery daily, or every other day. Embolization was discontinued when a total of 14 to 20 million spheres had been injected or if the fetus became acidotic or hypoxic (as defined above). In prior investigations the mean number of spheres required to successfully induce fetal growth retardation ranged between 12 and 17 million $(5,10)$.

Group ES fetuses were also begun on chronic femoral venous infusions of $5 \%$ glucose and $6.8 \%$ essential and nonessential Lamino acids (diluted from $8.5 \%$ Travasol, Travenol Laboratories, Deerfield, IL). The infusions were arbitrarily begun at volumes of 48 to $96 \mathrm{ml} /$ day and gradually increased, at variable rates, to provide a maximum of $160 \mathrm{ml} /$ day. Near term, the infusions were estimated to provide one-quarter to one-third of normal fetal nutrient needs $(11,12)$. Infusions were continued until spontaneous delivery, even if fetal $\mathrm{pH}$ or $\mathrm{PaO}_{2}$ decreased. In one fetus the rate of infusion was increased slowly because of persistent hypoxia and in two animals infusions were interrupted by pump malfunction.

Substrate and complete blood gas measurements were repeated weekly. Close to anticipated delivery, fetal umbilical blood flow was also measured, in duplicate, using a radiolabeled microsphere technique (8). Data for the final studies reported here were obtained a mean of 6 days (minimum 2 days) prior to delivery.

Animals born after 135 days gestation were considered as completing this study. These totalled eight in E, seven in ES, and eight in C. All were singletons except for an unexpected twin pair, divided between groups $\mathrm{E}$ and $\mathrm{C}$ at initial surgery. Fourteen additional animals died in utero or aborted early; six were in group $\mathrm{E}$, five in $\mathrm{ES}$, and three in $\mathrm{C}$.

At delivery, fetal weight, crown-rump length, and hindlimb length were measured. After fetal sacrifice, wet weights of individual organs were taken; gastrointestinal organs were cleaned before weighing. The organs were then dried at $80^{\circ} \mathrm{C}$ for $72 \mathrm{~h}$ and reweighed. The fetal placenta (afterbirth, consisting of fetal cotyledons and membranes) was collected and measured for wet and dry weights. Thereafter, it was carbonized and counted for radioactivity to calculate umbilical blood flow. The maternal uterus was inspected and also counted for radiolabel to be certain that there was no residual fetal, placental tissue. One placenta was lost and unavailable for analysis in both groups $\mathrm{E}$ and $\mathrm{C}$.

Analytical methods. All metabolites were analyzed in whole blood, in duplicate. The deproteinization steps in the assays for glucose, $\alpha$-amino nitrogen, lactate, and urea nitrogen were carried out with iced reagents, immediately after blood drawing. The supernatant obtained was frozen at $-40^{\circ} \mathrm{C}$. After delivery, samples from repetitive studies on the same animal were thawed and analyzed together in the same assay run. Amino nitrogen was determined by a colorimetric method involving the combination of $\alpha$-amino nitrogen groups on amino acids with bnapthoquinone sulfonate $(13,14)$. Glucose concentration was analyzed by an enzymatic, colorimetric glucose oxidase method, lactate by a lactate dehydrogenase assay and urea nitrogen by a colorimetric method (all from Sigma Chemical Co., St. Louis, MO). Our mean percentage error between duplicate fetal samples was $3.5 \%$ for $\alpha$-amino nitrogen, $2.6 \%$ for glucose, $1.8 \%$ for lactate, and $2.6 \%$ for urea nitrogen.

Blood gases were measured rapidly, after blood drawing, on a Corning $158 \mathrm{pH} /$ blood gas analyzer (Corning Medical, Medford, MA). Hemoglobin concentration and oxygen saturation were measured, in duplicate, on a Radiometer-Copenhagen OSM 2 hemoximeter (The London Co., Westlake, OH). Calibration of both machines was checked before each study. Our mean percentage error between duplicate measurements of hemoglobin was $1.0 \%$ and for oxygen saturation it was $0.8 \%$. Oxygen content was calculated using the formula: $\mathrm{O}_{2}$ content $(\mathrm{ml} / \mathrm{dl} \mathrm{blood})=$ $[1.34 \times$ hemoglobin $(\mathrm{g} / \mathrm{dl}) \times$ hemoglobin saturation $(\%)]+0.003$ $\times \mathrm{PaO}_{2}(\mathrm{~mm} \mathrm{Hg})(15)$. The accuracy of this method for determining oxygen content on fetal blood has been verified (16).

Blood flow to the placenta was measured using labeled microspheres (8). Microspheres were injected through the fetal femoral vein, while a reference sample of blood was withdrawn from the femoral artery at a known constant rate. After delivery, the placenta was counted for radioactivity and umbilical blood flow calculated, using the relationship: blood flow $(\mathrm{ml} / \mathrm{min})=[$ isotope counts in placenta/isotope counts in the reference sample] $\times$ reference sample flow $(\mathrm{ml} / \mathrm{min})$. The mean percentage error between the two umbilical flow measurements made during each study was $11 \%$.

Umbilical uptakes of nutrients and oxygen were calculated by multiplying the umbilical blood flow measurements by the umbilical venous-femoral arterial concentration differences found in the simultaneously drawn blood samples.

Changes that occurred over the treatment period in substrate levels and blood gases were evaluated by comparing the initial studies with the final studies.

Statistical analysis. All data are expressed as the mean \pm SEM. Comparisons were made between groups using one way analysis of variance and the unpaired $t$ test. $\chi^{2}$ analysis with Yates' correction was used to determine differences in the proportion of growth retarded fetuses in each group. Changes within a group between the initial and final observations were compared using the paired $t$ test. The correlation coefficient and regression analysis, by the least squares method, were used to define relationships between nutrient infusions, fetal and placental size, and fetal metabolite levels. Calculations were carried out using a Hewlett Packard 41 CV statistical package (Hewlett-Packard, Corvallis, OR).

\section{RESULTS}

Comparative information on the animals of E, ES, and C groups is provided in Table 1. The groups were similar with respect to the duration of study, period of placental embolization, the total number of microspheres injected, the male to female ratio, the gestation at delivery and initial fetal size, as judged by distal hindlimb length at surgery.

Initial maternal weights were not significantly different between groups, although mothers of surviving embolized fetuses tended to be slightly heavier. Prior to surgical preparation, weights averaged $55.3 \pm 2.8 \mathrm{~kg}$ in E, $52.0 \pm 4.0 \mathrm{~kg}$ in ES, and $48.5 \pm 1.9 \mathrm{~kg}$ in $\mathrm{C}$. The increase in maternal weight over the last 4 wk of gestation was similar in all groups and in the normal range for well nourished ewes (17). The mean change in weight was $7.4 \pm 1.2 \mathrm{~kg}$ in E, $8.9 \pm 1.2 \mathrm{~kg}$ in ES, and $8.1 \pm 1.4 \mathrm{~kg}$ in C. At birth, E fetuses were smaller than fetuses in ES or C. Measurements for all groups are provided in Table 2. Compared to controls, embolized animals had significantly decreased 
Table 1. Comparison of animal groups (mean $\pm S E M)$

\begin{tabular}{lccc}
\hline & $\mathrm{E}$ & $\mathrm{ES}$ & $\mathrm{C}$ \\
$(n=8)$ & $(n=7)$ & $(n=8)$ \\
\hline $\begin{array}{l}\text { Duration of study (days) } \\
\begin{array}{l}\text { Period of embolization } \\
\quad \text { days) }\end{array}\end{array}$ & $28 \pm 2$ & $27 \pm 2$ & $28 \pm 2$ \\
$\begin{array}{l}\text { Total microspheres in- } \\
\text { jected (millions) }\end{array}$ & $16 \pm 1$ & $15 \pm 1$ & None \\
$\begin{array}{l}\text { Male to female ratio } \\
\text { Gestation at delivery (days) }\end{array}$ & $140 \pm 2$ & $15 \pm 1$ & None \\
$\begin{array}{l}\text { Distal hindlimb length at } \\
\quad \text { surgery (cm) }\end{array}$ & $13.0 \pm 0.5$ & $13.2 \pm 0.4$ & $13.9 \pm 0.3$ \\
\hline
\end{tabular}

Table 2. Fetal size at birth (mean $\pm S E M)$

\begin{tabular}{lccc}
\hline & $\begin{array}{c}\mathrm{E} \\
(n=8)\end{array}$ & $\begin{array}{c}\mathrm{ES} \\
(n=7)\end{array}$ & $\begin{array}{c}\mathrm{C} \\
(n=8)\end{array}$ \\
\hline Fetal wt $(\mathrm{g})$ & $2888 \pm 373^{*}$ & $3601 \pm 190$ & $3880 \pm 277$ \\
Crown-rump length (cm) & $44.7 \pm 2.0$ & $45.8 \pm 0.9$ & $46.8 \pm 1.5$ \\
Ponderal index (wt/ & $3.1 \pm 0.1 \dagger \ddagger$ & $3.8 \pm 0.2$ & $3.8 \pm 0.1$ \\
$\quad$ length & $3.100)$ \\
Fetal/maternal wt (\%) & $5.2 \pm 0.6 \dagger \ddagger$ & $7.2 \pm 0.7$ & $8.0 \pm 0.6$ \\
Brain/body wt (\%) & $1.7 \pm 0.1^{*}$ & $1.5 \pm 0.1$ & $1.4 \pm 0.1$ \\
Distal hindlimb length & $17.1 \pm 0.8$ & $18.1 \pm 0.3$ & $18.9 \pm 0.4$ \\
$\quad(\mathrm{~cm})$ & & & \\
No. of fetuses $<2900 \mathrm{~g}$ & $5^{*} \ddagger$ & 0 & 0 \\
\hline
\end{tabular}

Compared to group $\mathrm{C}:{ }^{*} p<0.05, \dagger p<0.005$.

Compared to group ES: $\ddagger p<0.05$.

weights, ponderal indices, and fetal to maternal weight ratios. The $\mathrm{E}$ brain/body weight ratios were increased, indicating asymmetric intrauterine growth retardation (1-6). The number of $E$ fetuses who were markedly reduced in size, weighing less than $2900 \mathrm{~g}$, was also significantly different from group C. No control fetuses were this stunted.

In contrast, ES fetuses showed no significant differences in birth weight or size compared to control animals. ES fetuses were significantly larger than $E$ fetuses with respect to ponderal indices and fetal/maternal weight ratios. Further, there were no fetuses in the ES group weighing less than $2900 \mathrm{~g}$.

In the $\mathrm{E}$ and $\mathrm{ES}$ groups, the size achieved at birth was proportional to the quantity of nutritional supplements received. For $E$ and ES fetuses the average daily supplementation rate showed significant correlation with the fetal/maternal weight ratio and with the ponderal index, an indicator of fetal wasting. These relationships are presented in Figures 1 and 2 . Due to the variability in absolute birth weight of $E$ animals, the relationship between supplement rate and $\mathrm{E}$ and $\mathrm{ES}$ absolute birth weight fell short of achieving statistical significance $(r=0.50, p<0.06, n=$ 15). However, there was a strong correlation between supplement administration and birth weight in the ES group alone (Fig. 3).

The apparent relationship between nutrient supplementation and size at birth could not be explained by other experimental factors. There was no difference between groups in the number of microspheres injected. There was no correlation between size at birth and microsphere injections or between microsphere injections and the average supplementation rate. There was no difference in gestation at delivery between $E$ and ES animals and no correlation between age at delivery and the average supplementation rate. Further, ES fetuses showed no relationship between birth weight and gestation at delivery, so that larger fetuses were not just older. While $\mathrm{C}$ fetuses displayed a correlation between birth weight and initial hindlimb length $(r=0.78, p<$ $0.05, n=8$ ), this relationship was not found in groups $E$ or ES.

Fetal placental weight was markedly decreased in $E$ animals and greatest in group ES. The mean placental wet weights are given in Table 3 . Placental dry weights were also significantly reduced in $\mathrm{E}$ and had mean values of: $\mathrm{E}, 40.2 \pm 5.2 \mathrm{~g}$; ES, 73.4

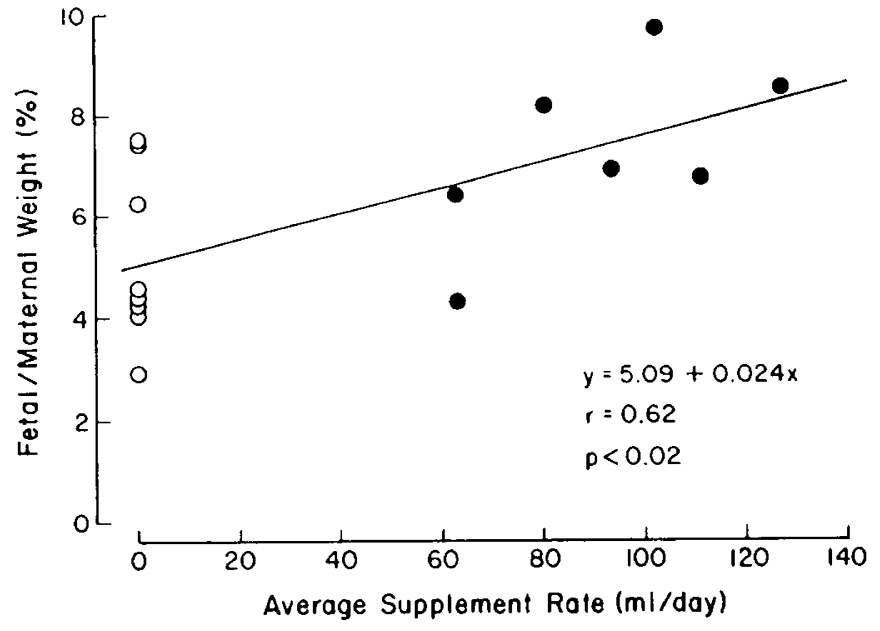

Fig. 1. The relationship between the fetal/maternal weight ratio and the average daily volume of supplement administered in embolized $(O)$ and embolized supplemented $(\bullet)$ fetuses.

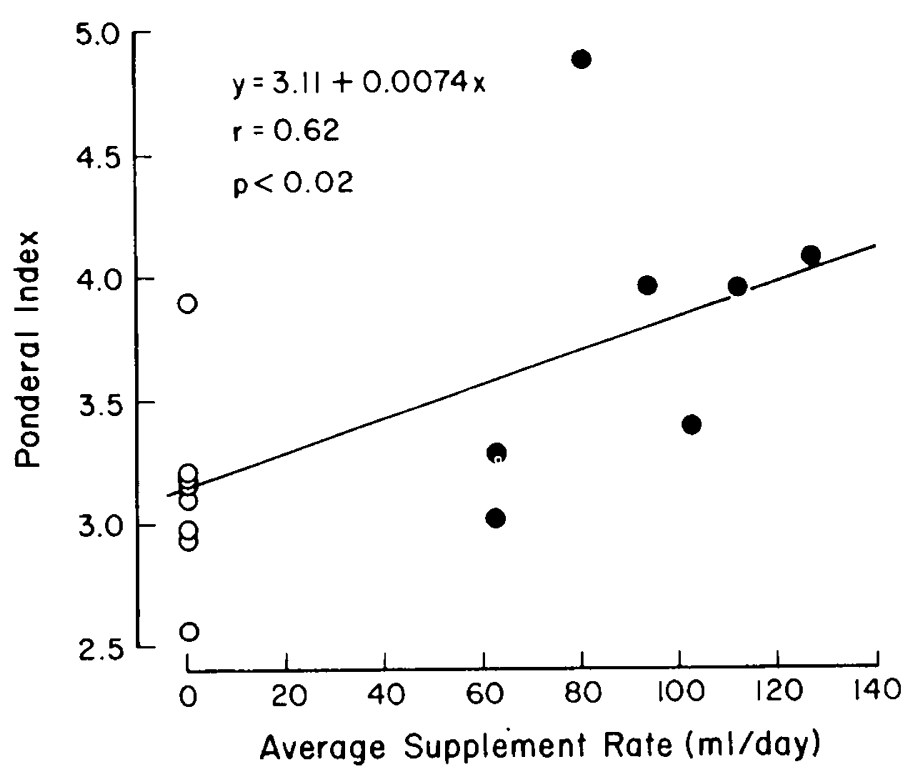

Fig. 2. The relationship between the ponderal index and the average daily volume of supplement administered in embolized $(O)$ and embolized supplemented $(\bullet)$ fetuses.

$\pm 12.2 \mathrm{~g}$, and $\mathrm{C}, 66.4 \pm 9.9(p<0.05 \mathrm{E}$ compared to $\mathrm{ES}$ and $\mathrm{C}$, $n=7$ for all groups). As is shown in Figure 4, placental size in $\mathrm{E}$ and ES fetuses correlated closely with the volume of supplements received by 130 days, or the mid-third trimester.

Fetal body organ weights were lowest in group E. Wet weights and the percentage change in organ weights, compared to mean control values, are given in Table 3. Comparisons using organ dry weights were similar. E fetuses showed reductions of 9 to $33 \%$ in body organ size. Due to the marked variability in individual animals, however, only the reduction in gastrointestinal tract weight achieved statistical significance. The organs least affected by the growth retardation process were the brain and adrenal glands.

Weights of most organs in ES fetuses were close to those of controls, as can be seen in Table 3 . Of note was the tendency to increased thymic and splenic size in the supplemented animals and a persistent reduction in gastrointestinal weight.

There were no differences between groups in initial maternal and fetal chemistries. Maternal metabolite levels and fetal me- 
tabolite and blood gas values are presented in Table 4 for all groups.

Over the month long study period, the only significant change in maternal chemistries was a small increase in blood lactate in group $\mathrm{C}(+2.0 \pm 0.8 \mathrm{mg} / \mathrm{dl}, p<0.05)$. Longitudinal alterations in fetal chemistries, between the initial and final studies, are listed in Table 5.

All fetal groups experienced a decrease in glucose concentration and an increase in lactate, but these changes were larger and reached statistical significance only in $\mathrm{E}$. Other significant within group changes in metabolites were an increase in urea nitrogen in ES and a rise in amino nitrogen in C. pH was stable but $\mathrm{PaO}_{2}$ and oxygen saturation fell in all groups. The steepest decline in oxygenation occurred in C and ES. However, a rise in hemoglobin concentration in these groups helped maintain fetal blood oxygen content. Despite the changes noted within groups, the between group differences in final metabolite levels were not statistically significant.

The average fetal level of each substrate, determined by averaging the weekly values, was compared to fetal size at birth. Using animals from all groups $(n=23)$, no significant correlation

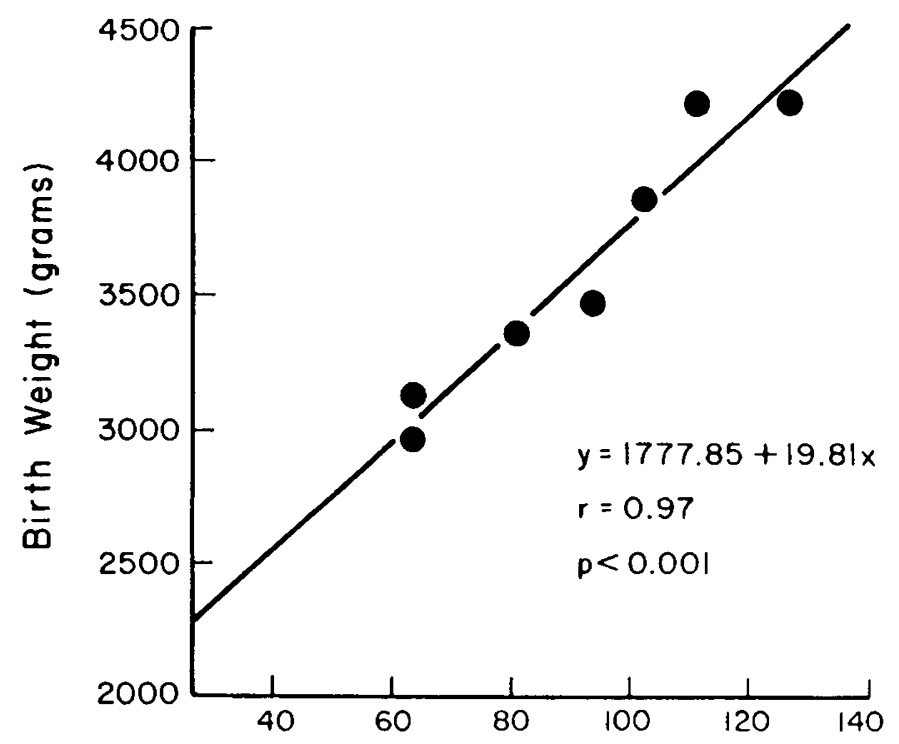

Average Supplement Rate ( $\mathrm{ml} /$ day)

Fig. 3. The relationship between birth weight and the average daily supplementation rate in embolized supplemented fetuses. was found between fetal birth weight and either mean glucose, amino nitrogen, or $\mathrm{PaO}_{2}$ levels.

In ES fetuses, comparisons were made between the quantity of supplements administered and fetal substrate levels. No correlations were found between the supplementation rate and either the mean fetal glucose concentration, amino nitrogen concentration, or $\mathrm{PaO}_{2}$.

Total umbilical blood flow near delivery was $27 \%$ lower in $\mathrm{E}$ than ES fetuses. Mean values for total umbilical flow were: 519 $\pm 55 \mathrm{ml} / \mathrm{min}$ in $\mathrm{E} ; 714 \pm 54 \mathrm{ml} / \mathrm{min}$ in $\mathrm{ES}$; and $636 \pm 43 \mathrm{ml} /$ min in $\mathrm{C}$ ( $p<0.05$ for $\mathrm{E}$ versus $\mathrm{ES}, n=7$ for all groups). In contrast, flow per $\mathrm{kg}$ of fetal birth weight was similar in all groups, averaging: $193 \pm 31 \mathrm{ml} / \mathrm{min} / \mathrm{kg}$ in E, $201 \pm 17 \mathrm{ml} / \mathrm{min} /$ $\mathrm{kg}$ in $\mathrm{ES}$, and $173 \pm 13 \mathrm{ml} / \mathrm{min} / \mathrm{kg}$ in $\mathrm{C}$.

Umbilical uptake of carbohydrates (glucose and lactate) and oxygen near delivery was measured in four fetuses in $\mathrm{E}$, four in $\mathrm{ES}$, and five in C. With the small number of animals studied, none of the differences noted among groups was statistically significant. However, the average umbilical uptakes of carbohydrates and oxygen were lowest in $\mathrm{E}$ and highest in $\mathrm{C}$. The mean values for carbohydrate uptake were $21.6 \pm 4.5 \mathrm{mg} / \mathrm{min}$ in $\mathrm{E}$, $26.7 \pm 1.1 \mathrm{mg} / \mathrm{min}$ in ES, and $31.3 \pm 2.0$ in C. The ES fetuses were receiving an additional $3.5 \pm 0.7 \mathrm{mg} / \mathrm{min}$ of glucose intravenously at the time of study, so that average entrance of

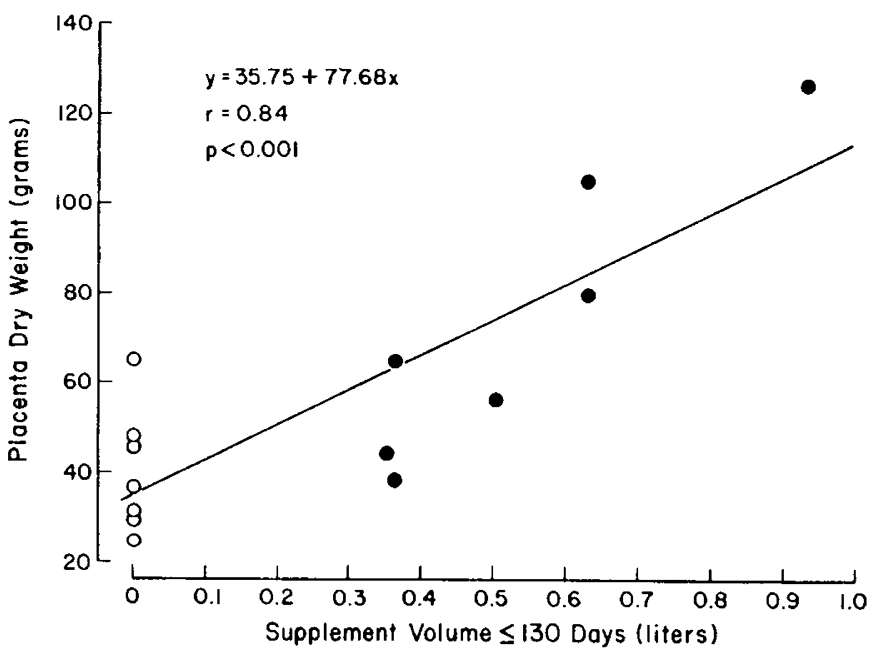

Fig. 4. The relationship between placental dry weight in embolized $(O)$ and embolized supplemented $(\bullet)$ fetuses and the volume of nutritional supplements administered by 130 days gestation.

Table 3. Fetal organ $w t(\text { mean } \pm S E M)^{*}$

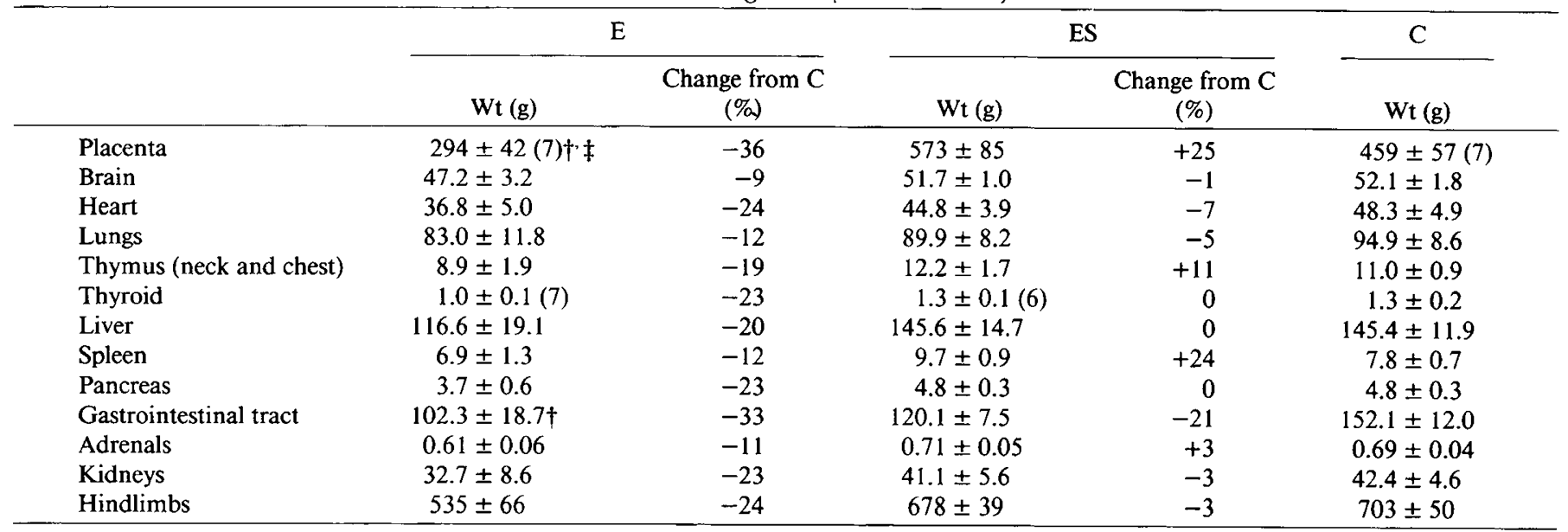

* Measurements were made in eight animals in E, seven in ES, and eight in C, except where noted in parentheses.

Compared to group $\mathrm{C}: \dagger p<0.05$.

Compared to group ES: $\ddagger p<0.02$. 
FETAL NUTRITIONAL SUPPLEMENTATION

Table 4. Initial fetal femoral arterial chemistries (mean $\pm S E M)^{*}$

\begin{tabular}{|c|c|c|c|}
\hline & $\mathrm{E}$ & ES & $\mathrm{C}$ \\
\hline \multicolumn{4}{|l|}{ Maternal arterial } \\
\hline Glucose (mg/dl) & $55.3 \pm 1.8$ & $54.0 \pm 1.1$ & $53.6 \pm 2.1$ \\
\hline$\alpha$-Amino nitrogen $(\mathrm{mg} / \mathrm{dl})$ & $5.3 \pm 0.2(7)$ & $5.4 \pm 0.4$ & $5.6 \pm 0.3$ \\
\hline Lactate $(\mathrm{mg} / \mathrm{dl})$ & $8.2 \pm 0.7$ & $9.0 \pm 0.7$ & $8.1 \pm 0.7$ \\
\hline Urea nitrogen $(\mathrm{mg} / \mathrm{dl})$ & $20.7 \pm 1.8(7)$ & $19.0 \pm 2.1(5)$ & $18.8 \pm 1.7(7)$ \\
\hline \multicolumn{4}{|l|}{ Fetal femoral arterial } \\
\hline Glucose $(\mathrm{mg} / \mathrm{dl})$ & $19.7 \pm 1.0$ & $20.2 \pm 1.7$ & $19.2 \pm 1.6$ \\
\hline$\alpha$-Amino nitrogen (mg/dl) & $7.5 \pm 1.2$ & $7.5 \pm 0.5$ & $8.0 \pm 0.5$ \\
\hline Lactate $(\mathrm{mg} / \mathrm{dl})$ & $12.4 \pm 0.6$ & $13.2 \pm 1.0$ & $14.1 \pm 0.8$ \\
\hline Urea nitrogen $(\mathrm{mg} / \mathrm{dl})$ & $21.1 \pm 1.8(7)$ & $17.7 \pm 2.4$ & $18.4 \pm 1.5(7)$ \\
\hline $\mathrm{pH}$ & $7.36 \pm 0.01$ & $7.36 \pm 0.01$ & $7.35 \pm 0.01$ \\
\hline $\mathrm{PaO}_{2}(\mathrm{~mm} \mathrm{Hg})$ & $20.7 \pm 0.5(7)$ & $20.7 \pm 0.9$ & $20.8 \pm 0.6$ \\
\hline Oxygen saturation (\%) & $53.2 \pm 1.6(7)$ & $52.7 \pm 2.5$ & $56.2 \pm 1.5$ \\
\hline Hemoglobin $(\mathrm{g} / \mathrm{dl})$ & $9.2 \pm 0.4$ & $9.1 \pm 0.4$ & $9.6 \pm 0.6$ \\
\hline Oxygen content $(\mathrm{ml} / \mathrm{dl})$ & $6.6 \pm 0.4(7)$ & $6.5 \pm 0.4$ & $7.2 \pm 0.4$ \\
\hline
\end{tabular}

* Measurements were made in eight animals in group E, seven in ES, and eight in C, except where noted in parentheses.

Table 5. Change in fetal chemistries (mean $\pm S E M)^{*}$

\begin{tabular}{|c|c|c|c|}
\hline & $\mathrm{E}$ & ES & $\mathrm{C}$ \\
\hline Glucose $(\mathrm{mg} / \mathrm{dl})$ & $-3.7 \pm 1.3 \dagger$ & $-2.6 \pm 1.1$ & $-2.2 \pm 1.1$ \\
\hline$\alpha$-Amino nitrogen $(\mathrm{mg} / \mathrm{dl})$ & $+1.2 \pm 0.9$ & $+0.8 \pm 0.7$ & $+0.5 \pm 0.2 \dagger$ \\
\hline Lactate $(\mathrm{mg} / \mathrm{dl})$ & $+7.5 \pm 2.7 \dagger$ & $+5.4 \pm 2.5$ & $+3.7 \pm 1.7(7)$ \\
\hline Urea nitrogen $(\mathrm{mg} / \mathrm{dl})$ & $+1.5 \pm 2.6(7)$ & $+6.2 \pm 2.0 \ddagger$ & $+1.5 \pm 1.9(7)$ \\
\hline $\mathrm{pH}$ & $0.00 \pm 0.01$ & $-0.004 \pm 0.01$ & $+0.01 \pm 0.01$ \\
\hline $\mathrm{PaO}_{2}(\mathrm{~mm} \mathrm{Hg})$ & $-2.2 \pm 0.8 \dagger(7)$ & $-2.6 \pm 1.2$ & $-3.2 \pm 0.7 \S$ \\
\hline Oxygen saturation (\%) & $-12.2 \pm 4.1 \dagger(7)$ & $-13.0 \pm 4.0 \ddagger(7)$ & $-15.5 \pm 3.9 \|$ \\
\hline Hemoglobin $(\mathrm{g} / \mathrm{dl})$ & $+0.5 \pm 0.2$ & $+1.2 \pm 0.3 \ddagger$ & $+1.5 \pm 0.5 \ddagger$ \\
\hline Oxygen content $(\mathrm{ml} / \mathrm{dl})$ & $-1.0 \pm 0.7(7)$ & $-1.0 \pm 0.5$ & $-1.2 \pm 0.7$ \\
\hline
\end{tabular}

* Measurements were made in eight animals in group E, seven in ES, and eight in C, except where indicated by parentheses.

Significance of within group change from initial to final studies: $\dagger p<0.05, \ddagger p<0.02, \S p<0.005, \| p<0.01$.

carbohydrate into these animals was $30.2 \pm 1.3 \mathrm{mg} / \mathrm{min}$ and close to controls. Oxygen uptake averaged $21.0 \pm 2.9 \mathrm{ml} / \mathrm{min}$ in $\mathrm{E}$, $26.6 \pm 2.4 \mathrm{ml} / \mathrm{min}$ in $\mathrm{ES}$, and $26.7 \pm 1.8 \mathrm{ml} / \mathrm{min}$ in C.

\section{DISCUSSION}

Decreased transfer of nutrients into the developing fetus has been identified in many forms of experimental intrauterine growth retardation $(2,3,5,7)$. We have, therefore, been investigating the extent to which nutrient availability influences fetal growth, by providing nutritional supplements to fetuses subjected to growth retarding procedures. Fetal intragastric infusions of glucose and amino acids were found to normalize fetal, but not placental, size at birth in fetal lambs from diet restricted mothers (3). However, the maternal malnutrition protocol followed in that study only produced a moderate form of growth retardation. Birth weight in unsupplemented lambs was reduced $18 \%$ while placental weight was reduced $28 \%$ (3).

The current study was undertaken to evaluate the effects of intrauterine nutritional supplements in fetuses subjected to a more severe growth retarding procedure, placental damage by repetitive uterine microembolization. In past investigations, fetuses subjected to this growth retardation method have been reduced approximately $30 \%$ in weight while placental size has been decreased 30 to $40 \%(10,18,19)$. The second aim of this study was to determine whether direct intravenous infusion of nutrients would have similar fetal effects as intragastric supplementation. Nutrients administered into the fetal gastrointestinal tract pass through the right lobe of the liver before entering the general circulation and may potentially influence or be regulated by hepatic metabolism (20). The results of this investigation indicate that intravenous supplementation will prevent embolization-induced growth retardation. Further, femoral infusion of nutrients are well tolerated and maintain placental size.

$C$ fetuses in this study were of similar weight, brain to body weight ratios, and ponderal index as normal fetuses in past investigations $(3-5,18)$. Umbilical blood flow near delivery and uptakes of carbohydrate and oxygen were the same as values previously reported in healthy animals $(3,5,11,12)$.

In $E$ animals, as was expected, absolute fetal weight was reduced $26 \%$ compared to $C$. Fetal weight, relative to maternal weight, was reduced $35 \%$. In addition, E fetuses had other stigmata of growth retardation such as a reduced ponderal index and increased brain to body weight ratio $(5,18)$. The relative sparing of brain and adrenal growth found in these animals is characteristic of ovine growth retardation induced by multiple experimental methods $(3-5,18,21)$. Most of the organs found to be decreased in mean weight were those previously reported to be affected by ovine growth retarding procedures $(3,18,21)$. However, the large decrease in gastrointestinal weight has not been mentioned in previous ovine studies, where enteric weights are often omitted. A pronounced effect of our procedures on gastrointestinal size is not surprising, since ovine gastrointestinal organs normally undergo a large proportion of their growth in the late 3rd trimester (22).

The $\mathrm{E}$ fetuses also displayed physiologic changes previously associated with intrauterine growth retardation in the sheep. These included a reduction in total umbilical blood flow $(5,19,23,24)$, and a more consistent decrease in blood glucose $(3,4,6)$ and increase in lactate $(5)$ than were found in other groups.

In several prior studies, fetuses growth retarded by placental embolization have developed significant hypoxia when compared to control animals $(5,18)$, but this finding has not been uniform (23). In the current study, while fetal arterial oxygen tension and saturation fell in $E$ animals, these changes were found to the same or greater extent in $C$ animals. The higher attrition rate in the $\mathrm{E}$ group may have eliminated the more poorly oxygenated fetuses but pronounced hypoxia was not documented as accompanying embolization in our studies. 
Infusion of glucose and amino acid supplements prevented the development of growth retardation in the embolized, fetal supplementation (ES) group. While comparable to the E fetuses in initial characteristics and embolization protocol, ES fetuses ended up close to $C$ in size and body proportions. Only gastrointestinal weight tended to remain small. The increase in spleen and thymus weights may have been due to increased hematopoesis and nutritional reversal of the lymphoid tissue atrophy, which accompanies malnutrition (25).

No toxic effects of supplementation were apparent in ES fetuses. There was a decrease in fetal $\mathrm{PaO}_{2}$ and oxygen saturation, similar to that experienced by other groups, but acidosis, previously noted in oxygen compromised fetuses given acute infusions of glucose (26), did not develop. In these chronic studies, fetal oxygenation was maintained by appropriate increases in hemoglobin. An elevation in ES urea nitrogen did occur. This was likely due to catabolism of those amino acids in the infusion mixture which may have been administered in excess.

In $E$ and $E S$ animals, size at birth correlated with the administration of intrauterine nutritional supplements. Apart from the general increase in nutrients and calories provided by infusions, no specific factors were identified as influencing fetal growth. No direct relationships were found between fetal size at birth and average in utero levels of glucose, amino nitrogen, or oxygen, nor was there a correlation between the supplementation rate and average fetal levels of these metabolites. However, in studies in which growth retardation has been produced by uterine carunclectomy, correlations have been reported between birth weight and mean fetal glucose and mean $\mathrm{PaO}_{2}$ (6). A linear relationship between birth weight and the average daily quantity of glucose calories administered has also been found in groups of normal rabbit pups given 3rd trimester intraamniotic infusions of glucose (27).

The most striking effect of femoral venous nutrient administration noted in the current study was the enhanced size of the fetal placenta (or afterbirth) in the ES animals. While E fetuses showed the large $36 \%$ reduction in placental weight that is expected in the embolization model $(10,19)$, placental weight was normal or increased in fetuses receiving supplementation. There may have been both stimulation of placental growth in ES animals and prevention of embolization-induced placental regression. In the sheep, during the 3rd trimester, the fetal portion of the placental cotyledons shows a small increase in weight and the relative proportion of fetal to maternal cotyledonary tissue increases $(17,28)$. The weight of fetal membranes, particularly the chorion and allantois, also increase (17). The close correlation we observed between placental size and the quantity of supplements infused before 130 days gestation suggests that any stimulatory effects nutrients have on placental growth were limited to the first portion of the 3rd trimester.

A marked regression in ovine cotyledonary weight normally occurs after unilateral uterine embolization; this begins to be apparent within $24 \mathrm{~h}$ after the first microsphere injection (10). Cotyledonary weight is reduced in both pregnant (embolized) and nonpregnant (nonembolized) uterine horns, but the reduction in the embolized side is more severe (10). Nutritional supplementation prevented this regression in ES animals so that fetal placental weight was maintained. Since placenta was not collected separately from the two uterine horns during this study, no information is available on any differences that may have occurred in tissue weight on the embolized versus nonembolized sides.

Improved placental size in the ES fetuses, to a large extent, may have determined their improved outcome. Umbilical blood flow remained at normal levels and oxygen uptake was sufficient to allow utilization of endogenous and exogenous nutrients.

Maintenance of placental size was not observed in nutrientsupplemented animals in our prior dietary restriction study (3). Malnourished fetuses given intragastric nutritional infusions had a reduction in placental size almost equal to that in nonsupple- mented, malnourished animals. Provision of nutrients via the femoral vein and inferior vena cava in the current study, however, would have resulted in a different pattern of distribution for the infused nutrients. Forty percent of blood returning to the fetal heart through the inferior vena cava is directed out again to the placenta (29). Femoral venous supplementation, therefore, would result in considerable "dosing" of the fetal side of the placenta by our infused nutrients.

This study suggests that nutrients provided by a fetal femoral venous route are well tolerated and can be utilized to prevent the development of fetal and placental growth retardation, induced by repetitive placental embolization. Under the conditions of our study, fetal growth appeared to be limited by nutritional availability but the specific nutritional factors leading to impaired growth could not be identified. Further, despite decreases in fetal oxygen levels, our embolized animals did not become markedly hypoxic. The effects of nutrient supplements on the severely hypoxic fetus, in whom oxygen availability may become growth limiting (30), could not, therefore, be evaluated.

\section{REFERENCES}

1. Cassady G 1981 The small for date infant. In: Avery GB (ed) Neonatology, 2nd ed. JB Lippincott, Philadelphia, pp 262-301

2. Chariton V 1986 Nutritional supplementation of the growth retarded fetus: rationale, theoretical considerations and in vivo studies. In: Milunsky A, Friedman E, Gluck L (eds). Advances in Perinatal Medicine, Vol 5. Plenum, New York, pp 1-42

3. Charlton V, Johengen M 1985 Effects of intrauterine nutritional supplementation on fetal growth retardation. Biol Neonate 48:125-142

4. Robinson JS, Kingston EJ, Jones CT, Thorburn GD 1979 Studies on experimental growth retardation in sheep. The effect of removal of endometrial caruncles on fetal size and metabolism. J Dev Physiol 1:379-398

5. Clapp JF, Szeto HH, Larrow R, Hewitt J, Mann LI 1981 Fetal metabolic response to experimental placental vascular damage. Am J Obstet Gynecol 140:446-451

6. Harding JE, Jones CT, Robinson JS 1985 Studies on experimental growth retardation in sheep. The effects of a small placenta in restricting transport to and growth of the fetus. J Dev Physiol 7:427-442

7. Nitzan M, Orloff S, Schulman J 1979 Placental transfer of analogs of glucose and amino acids in experimental intrauterine growth retardation. Pediatr Res 13:100-103

8. Rudolph AM, Heymann MA 1980 Methods for studying the circulation in utero. In: Nathanielsz PW (ed) Animal Models in Fetal Medicine I. Elsevier/ North Holland, New York, pp 1-57

9. Novy MJ, Walsh SW, Cook MJ 1980 Chronic implantation of catheters and electrodes in pregnant nonhuman primates. In: Nathanielsz PW (ed) Anima Models in Fetal Medicine I. Elsevier/North Holland, New York, pp 133168

10. Clapp JF, McLaughlin M, Larrow R, Farnham J, Mann LI 1982 The uterine hemodynamic response to repetitive unilateral vascular embolization in the pregnant ewe. Am J Obstet Gynecol 144:309-318

11. Hay WW, Sparks JW 1985 Placental, fetal, and neonatal carbohydrate metabolism. Clin Obstet Gynecol 28:473-485

12. Charlton V, Reis B 1981 Effects of gastric nutritional supplementation on fetal umbilical uptake of nutrients. Am J Physiol 241:E178-185

13. Frame GG, Russell JA, Wilhemi AE 1943 The colorimetric estimation of amino nitrogen in blood. J Biol Chem 149:255-270

14. Rusell JA 1944 Note on the colorimetric determination of amino nitrogen. J Biol Chem 150:467-468

15. Comroe J 1975 The transport of oxygen by blood. In: The Physiology of Respiration. Yearbook Medical, Chicago, pp 183-196

16. McKinney RJ, Harris EA 1978 Evaluation of the $\mathrm{OSM}_{2}$ hemoximeter. Cardiovasc Res 12:630-634

17. Wailace LR 1948 The growth of lambs before and after birth in relation to the level of nutrition. Parts II and III. J Agric Sci 38:243-302

18. Creasy RK, Barrett CT, DeSwiet M, Kahanpaa KV, Rudolph AM 1972 Experimental intrauterine growth retardation in the sheep. Am J Obstet Gynecol 112:566-573

19. Creasy RK, DeSwiet M, Kahanpaa KV, Young WP, Rudolph AM 1973 Pathophysiological changes in the foetal lamb with growth retardation. In: Cross KW (ed) Foetal and Neonatal Physiology. Sir Joseph Barcroft Centenary Symposium. Cambridge University Press, Cambridge, pp 398-402

20. Edelstone D, Rudolph AM, Heymann M 1978 Liver and ductus venosus blood flows in fetal lambs in utero. Circ Res 42:426-433

21. Koritnik D, Humphrey W, Kaltenbach C, Dunn T 1981 Effects of maternal undernutrition on the development of the ovine fetus and associated changes in growth hormone and prolactin. Biol Reprod 24:125-137

22. Barcroft J 1946 Growth of the body and its constituent parts. In: Researches on Pre-natal Life. Blackwell Scientific, Oxford, pp 29-41

23. Clapp JF, Szeto HH, Larrow R, Hewitt J, Mann LI 1980 Umbilical blood flow response to embolization of the uterine circulation. Am J Obstet Gynecol 138:60-67 
24. Oh W, Omori K, Hobel CJ, Erenberg A, Emmanouilides GC 1975 Umbilical blood flow and glucose uptake in the lamb fetus following single umbilical artery ligation. Biol Neonate 26:291-299

25. Beisel W, Edelman R, Nauss K, Suskind R 1981 Single nutrient effects on immunologic function. JAMA 245:53-58

26. Shelly $\mathbf{H}$, Bassett J, Milner R 1975 Control of carbohydrate metabolism in the fetus and newborn. Br Med Bull 31:37-43

27. Mulvihill SJ, Albert A, Synn A, Fonkalsrud E 1985 In utero supplemental fetal feeding in an animal model: effects on fetal growth and development. Surgery 98:500-505

28. Alexander G 1964 Studies in the placenta of the sheep. Placental size. J Reprod Fertil 7:289-305

29. Edelstone DI, Rudolph AM 1979 Preferential streaming of ductus venosus blood to the brain and heart in fetal lambs. Am J 'hysiol 237:H724-729

30. Villeisis RA 1985 Effect of maternal oxygen inhalation on the fetus with growth retardation. Pediatr Res 19:324-327 